\section{vopact HORIZON}

PENDIDIKAN

JURNAL HORIZON PENDIDIKAN

Publish by: Library of STKIP PGRI Sumatera Barat

E-ISSN : 2775-5770

Vol. 1 No. 4 (November 2021) (647-657)

http://ejournal.stkip-pgri-sumbar.ac.id/index.php/horizon

\title{
PELAKSANAAN STUDENT CENTERED LEARNING BERBASIS DARING PADA PEMBELAJARAN SOSIOLOGI SISWA KELAS X IPS SMA PGRI 4 PADANG PADA MASA PANDEMI COVID-19
}

\author{
Muhammad Hafiz Ardyanli, Yanti Sri Wahyuni, Hefni \\ Program Studi Pendidikan Sosiologi STKIP PGRI Sumatera Barat \\ muahmmadhafizandryanli@gmail.com
}

Submitted: 28-10-2021, Reviewed: 29-10-2021, Accepted: 05-11-2021

\begin{abstract}
The background of the problem in the study is as follows: On March 17, 2020, the principal and head of the Padang city education office and the head of the West Sumatra 1 regional education office branch held a meeting in which one of the results was the dismissal of all levels of education and the teaching and learning process was shifted from face to face to face-to-face. online learning. The approach in this study is a descriptive research type Descriptive research type is a method to understand the individual that is carried out in an integrative and comprehensive manner in order to obtain a deep understanding of the individual and the problems he faces with the aim of solving the problem and obtaining improvement. good self-esteem. The informants of this study were the curriculum representatives and Mr. Sociology subject teacher for class X, namely those who taught in class X IPS 1, 2, SMA PGRI 4 Padang. The results of the study were carried out with Sociology Teachers, the online learning process lasted for 5 weeks at SMA PGRI 4 Padang. Therefore, for 5 weeks, he carried out student centered learning based on online learning. The researchers concluded that Student Centered Learning could be implemented but it was not effective by using WhatsApp groups only, teachers should also use other applications, such as Google Classroom, Zoom, Telegram, Email, Telegram, Web Links provided by the school. So that the learning process can take place better.
\end{abstract}

\section{Keywords: Student Cendetered Learning, Daring.}

\section{PENDAHULUAN}

Student Centered Learning (SCL)

merupakan suatu pendekatan

pembelajaran yang menempatkan

siswa sebagai subjek belajar dan

kegiatan belajar bersifat modern.

Pendekatan pembelajaran yang

berorientasi pada siswa, manajemen, dan pengelolaannya ditentukan oleh siswa. Pada pendekatan ini siswa memiliki kesempatan yang terbuka untuk melakukan kretivitas dan mengembangkan potensinya melalui aktivitas secara langsung sesuai dengan minat dan keinginannya Nursobah, 2018). 


\section{vopact HORIZON}

PENDIDIKAN

JURNAL HORIZON PENDIDIKAN

Publish by: Library of STKIP PGRI Sumatera Barat

E-ISSN : 2775-5770

Vol. 1 No. 4 (November 2021) (647-657)

http://ejournal.stkip-pgri-sumbar.ac.id/index.php/horizon

Dalam proses pembelajaran secara Daring (online) ini memberikan banyak sekali dampak, mulai dari dampak positif hingga dampak negatif. Pembelajaran secara Daring (online) ini dituntut untuk mempersiapkan pembelajaran sebaik dan sekreatif mungkin dalam memberikan suatu materi.

Hal di atas juga sesuai dengan pendapat M. Fadlillah (dalam Nursobah, 2018), mengenai lima prinsip yang harus diperhatikan guru dalam melaksanakan pembelajaran kurikulum 2013, diantaranya (1) berpusat pada siswa, mengembangkan kreativitas siswa, menciptakan kondisi menyenangkan dan menantang, (4) bermuatan nilai, etika, estetika, logika, dan kinestetika, menyediakan pengalaman belajar yang beragam melalui penerapan berbagai starategi dan metode pembelajaran yang menyenangkan, kontekstual, efektif, efisien dan bermakna.

Tujuan pembelajaran sosiologi pada kurikulum 2013 adalah meningkatkan penguasaan pengetahuan sosiologi dikalangan siswa yang berorientasi pada pemecahan masalah dan pemberdayaan sosial.

(Kemendikbud RI. Permendikbud Nomor 103 Tahun 2014 tentang Pembelajaran Pada Pendidikan Dasar dan Pendidikan Menengah. Published online 2014)

Berdasarkan wawancara yang dilakukan dengan Bapak Amril selaku wakil kurikulum SMA PGRI 4 Padang, tanggal 17 Maret 2020 Kepala Sekolah dan Kepala Dinas Pendidikan Kota Padang serta Kepala Cabang Dinas Pendidikan Wilayah 1 Sumatera Barat melakukan rapat dimana salah satu hasilnya dengan diliburkannya seluruh jenjang pendidikan dan proses belajar mengajar dialihkan dari tatap muka ke pembelajaran online. Hal ini dilakukan karena semakin mewabahnya Covid-19 di Indonesia. Berdasarkan hasil keputusan rapat tersebut, tanggal 18 Maret 2020 Kepala Sekolah SMA PGRI 4 Padang mengeluarkan kebijakan untuk melakukan proses pembelajaran di rumah dengan sistem Daring (online) maupun Luring (offline). Kemudian peneliti 
Publish by: Library of STKIP PGRI Sumatera Barat

E-ISSN : 2775-5770

Vol. 1 No. 4 (November 2021) (647-657)

http://ejournal.stkip-pgri-sumbar.ac.id/index.php/horizon

juga melakukan wawancara dengan salah satu guru sosiologi SMA 4 PGRI Padang melalui sambungan telepon yang direkam secara audio dan kemudian ditranskip secara verbal, beliau mengatakan bahwa SMA PGRI 4 Padang mulai melakukan pembelajaran online pada hari Senin, 23 Maret 2020. Proses pembelajaran yang akan dilaksanakan berpedoman pada hasil rapat majelis guru SMA PGRI 4 Padang.

Berdasarkan rumusan masalah, maka tujuan penelitian ini adalah untuk mendeskripsikan pelaksanaan Student Centered Learning berbasis online dan untuk mengetahui kendalakendala yang dihadapi dalam pelaksanaan Student Centered Learning berbasis online learning (Studi Kasus: Pembelajaran Sosiologi Siswa Kelas X IPS SMA PGRI 4 Padang Masa Pandemi Covid-19).

\section{METODE PENELITIAN}

Pendekatan dalam penelitian ini adalah pendekatan kualitatif dengan tipe penelitian deskriptif Tipe penelitian deskriptif adalah suatu metode untuk memahami individu yang dilakukan secara integratif dan komprehensif agar diperoleh pemahaman yang mendalam tentang individu tersebut beserta masalah yang dihadapinya dengan tujuan masalahnya dapat terselesaikan dan memperoleh perkembangan diri yang baik (Bungin B).

Bertolak dari penjelasan di atas maka penelitian ini termasuk jenis penelitian kualitatif dengan tipe deskriptif yang akan memberikan pemahaman yang mendalam tentang masalah yang dihadapi agar dapat memberikan gambaran yang menyeluruh dan mendalam tentang bagaimana pelaksanaan student centered learning berbasis online pada pembelajaran sosiologi siswa kelas X IPS SMA PGRI 4 Padang masa pandemi Covid-19.

Informan dari penelitian ini adalah wakil kurikulum dan Bapak guru mata pelajaran sosiologi kelas $\mathrm{X}$ yaitu yang mengajar di kelas $\mathrm{X}$ IPS 1, 2, SMA PGRI 4 Padang. Teknik pengumpulan data yang akan digunakan dalam penelitian ini adalah observasi atau pengamatan, wawancara mendalam (indepth interview), dan dokumentasi.Untuk menguji kredibilitas data penelitian, 


\section{Jovach HORIZON}

PENDIDIKAN

\section{JURNAL HORIZON PENDIDIKAN}

Publish by: Library of STKIP PGRI Sumatera Barat

E-ISSN : 2775-5770

Vol. 1 No. 4 (November 2021) (647-657)

http://ejournal.stkip-pgri-sumbar.ac.id/index.php/horizon

peneliti menggunakan teknik

triangulasi. Triangulasi. Penelitian ini menggunakan analisis data dari model

Miles dan Hubberman.

\section{HASIL DAN PEMBAHASAN}

A. Pelaksanaan Student Centered Learning Berbasis Daring

Berdasarkan kebijakan di atas mulai tanggal 19 Maret guru dan siswa melakukan proses pembelajaran secara Daring dan dibuat juga grup WhatsApp kelas serta grup WhatsApp masing-masing mata pelajaran. Karena persiapan terlalu minim tanggal 19, 20 dan 21 Maret yang dilakukan guru hanya memberikan informasi tentang pandemi Covid-19, tentang bidang-bidang studi dan jadwal pembelajaran kepada siswa melalui grup WhatsApp tersebut. Selain itu guru juga memberikan informasi kepada orang tua murid mengenai proses pembelajaran Daring melalui grup WhatsApp. Kemudian pembelajaran mulai dilakukan serentak untuk semua mata pelajaran tanggal 23 Maret 2020.

Berdasarkan wawancara yang peneliti lakukan dengan Guru Sosiologi proses pembelajaran Daring berlangsung selama 5 Minggu di SMA PGRI 4 Padang. Oleh karena itu, selama 5 Minggu itulah beliau melaksanakan student centered learning berbasis online learning. Proses pembelajaran Daring yang dilaksanakan oleh Guru tersebut hanya melalui WhatsApp group sesuia yang dikatakan oleh beliau saat melakukan wawancara denagan peneliti.

Adapun hal-hal yang dilakukan oleh SMA PGRI 4 Padang dalam menindaklanjuti hasil rapat Kepala Sekolah dan Kepala Dinas Pendidikan Kota Padang Barat sebagai berikut.

1. Melaksanakan Tatap Muka

Pada tanggal 19 Maret 2020 diadakan guru melaksanakan untuk mebicarakan model Daring dan penugasan untuk siswa selama proses belajar mengajar online. Berdasarkan hasil wawancara yang peneliti peroleh wakil kurikulum, yaitu (1) proses pembelajaran dilakukan online dilakukan melalui aplikasi WhatsApp, Google Classroom, Email, Telegram dan Link Web yang disediakan oleh sekolah dan media yang digunakan 
Publish by: Library of STKIP PGRI Sumatera Barat

E-ISSN : 2775-5770

Vol. 1 No. 4 (November 2021) (647-657)

http://ejournal.stkip-pgri-sumbar.ac.id/index.php/horizon

tergantung masing-masing guru yang bersangkutan kalau guru yang bersangkutan bisanya google classroom maka pakai google classroom, kalau gurunya bisa ad modul maka pakai ad modul dan ada yang hanya pakai WhatssApp., memberikan informasi kepada orang tua siswa melalui WhatsApp kelas bahwa pembelajaran dilakukan secara Daring, (3) sekolah menyediakan absensi guru dan siswa dalam bentuk google form, (4) guru harus melaporkan setiap satu kali dalam seminggu mengenai kehadiran siswa, materi apa yang dilakukan dalam proses belajar mengajar dan penugasan yang diberikan dalam bentuk laporan pembelajaran Daring, (4) pembelajaran Daring dimulai pukul 07.30 dan diakhiri pukul 13.30, (6) absensi siswa dan guru selama pandemi menggunakan google form, jadi dibedakan antara absensi guru dg siswa, (5) jadwal belajar mengajar tetap menggunakan jadwal yang lama tetapi porsinya diubah dari 1 jam pelajaran itu biasanya 45 menit maka dijadikan 1 jam pelajran itu 30 menit.

2. Melaksanakan Pembelajaran a. Menghitung Minggu Efektif yang Tersisa

Kondisi pembelajaran pada masa pandemi Covid-19 di SMA PGRI 4 Padang yaitu dilakukan perubahan pada proses pendidikan di semester Genap, yang mana perubahan tersebut dapat dilihat pada tabel penghitungan minggu efektif belajar pada masa pandemi Covid-19 di semester Genap yang berpedoman pada kalender pendidikan provinsi Sumatera Barat tahun ajaran 2019/2020 serta penghitungan kembali minggu efektif yang sudah dilakukan oleh SMA PGRI 4 Padang. Adapun penghitungan minggu efektif belajar pada masa pandemi Covid-19 di SMA PGRI 4 Padang sebagai berikut.

Hal ini dapat dilihat bahwa minggu efektif belajar di semester II (Genap) pada masa pandemi Covid19 di SMA PGRI 4 Padang adalah 5 Minggu. Pada bulan Maret hanya ada 1 Minggu efektif yaitu tanggal 23 Maret sampai 31 Maret. Kemudian di bulan April ada 3 Minggu efektif yaitu tanggal 1 April sampai tanggal 21 April sedangkan 
Publish by: Library of STKIP PGRI Sumatera Barat

E-ISSN : 2775-5770

Vol. 1 No. 4 (November 2021) (647-657)

http://ejournal.stkip-pgri-sumbar.ac.id/index.php/horizon

2 Minggu tidak efektif disebabkan oleh libur awal Ramadhan dan Pesantren Ramadhan. Kemudian ada 1 Minggu efektif di bulan Mei yaitu dari tanggal 12 Mei sampai tanggal 20 Mei yang mana pada saat itu proses belajar mengajar secara Daring (online) mulai dilakukan lagi sedangkan 3 Minggu tidak efektif disebabkan oleh pelaksanaan pesantren Ramadhan mulai tanggal 27 April sampai 11 Mei dan libur idul fitri mulai tanggal 22 Mei sampai 30 Mei dan tanggal tanggal 5 Juni sampai tanggal 13 Juni diadakan Penilaian Semester dan Penilaian Akhir Tahun Pelajaran.

b. Jam Pelajaran

Jadwal belajar mengajar di SMA PGRI 4 Padang selama pandemi Covid-19 tetap menggunakan jadwal mengajar guru yang lama tetapi porsinya diubah dari 1 jam pelajaran itu biasanya 45 menit maka dijadikan 1 jam pelajaran itu 30 menit. Hal ini dilakukan karena proses pembelajaran Daring yang dilakukan bersifat mendadak dan tiba-tiba, sehingga semua majelis guru sepakat untuk tetap menggunakan jadwal belajar mengajar yang sudah disusun sebelumnya untuk semester genap tahun ajaran 2019/2020. Kemudian pembelajaran Daring dimulai pukul 07.30 dan diakhiri pukul 13.30. Hal ini sesuai yang dikatakan oleh wakil kurikulum, beliau mengatakan bahwa:

Jadi, berdasarkan hasil wawancara di atas guru-guru di SMA PGRI 4 Padang tetap melakukan proses belajar mengajar sesuai jadwal masing-masing yang sudah disusun sebelumnya untuk semester genap tahun ajaran 2019/2020, tetapi jam porsi jam pelajran dikurangi yang semula 1 jam pelajaran 45 menit maka diperpendek menjadi 30 menit untuk 1 jam pelajaran.

c. Melaksanakan Materi Pembelajaran

Materi yang diberikan selama proses belajar mengajar Daring di SMA PGRI 4 Padang berpedoman pada silabus yang sudah disiapkan sebelumnya. Tetapi kompetensi dasar dan indikator-indikator pembelajaran yang diajarkan tidak terlalu rumit atau dipermudah sehingga tujuan pembelajaran tercapai dan siswa juga tidak 
HORIZON

PENDIDIKAN

JURNAL HORIZON PENDIDIKAN

Publish by: Library of STKIP PGRI Sumatera Barat

E-ISSN : 2775-5770

Vol. 1 No. 4 (November 2021) (647-657)

http://ejournal.stkip-pgri-sumbar.ac.id/index.php/horizon

kewalahan

mengikuti

proses

pembelajaran

secara

Daring.

Sedangkan untuk RPP Daring tidak ada karena pembelajaran Daring ini sifatnya mendadak sehingga persiapan minim.

Kendala-kendala dalam

Pelaksanaan Student Centered

Learning Berbasis Daring pada Pembelajaran Sosiologi Siswa Kelas X IPS Masa Pandemi Covid-19.

Berdasarkan wawancara yang telah peneliti lakukan dengan guru mata pelajaran sosiologi dan siswasiswa kelas $\mathrm{X}$ IPS SMA PGRI 4 Padang ada kendala-kendala yang yang dirasakan oleh guru dan siswa dalam pembelajaran sosiologi adalah.

\section{Pengalokasian Waktu}

Pada proses pembelajaran Daring waktu yang dirasakan guru dan siswa sedikit karena porsi jam pembelajaran diperpendek yang semula 1 jam pelajaran 45 menit menjadi 1 jam pelajaarn 30 menit. Kemudian waktu yang tersedia hanya 3 SKS dan guru harus melakukan proses pembelajaran selama 3 SKS tersebut secara Daring. Karena interaksi antara guru dan siswa tidak terjadi secara langsung dan sistem sekolah formal maka terkadang waktu jam belajar ini molor. Dimana lamanya waktu untuk absensi yang dilakukan oleh siswa. Guru susah mengkondisikan siswa untuk masuk kelas tepat pada waktunya dimana guru tidak mengetahui kapan siswa masuk kelas, apakah siswa masuk kelas. Hal ini terjadi karena proses pembelajaran hanya menggunakan WhatsApp Group.

Karena pembelajaran dilakukan secara Daring melalui WhatsApp Group, sehingga penerapan student centered learning ini agak susah terutama mengatur waktu jam pelajaran dan absensi . mulai jam pelajarannya sering molor, tugas tidak bisa diatur, kapan siswa mengumpulkan tugas dan berapa lama siswa mengumpulkannya. Sehingga proses pembelajaran tidak efektif, tidak semua materi pembelajaran bisa didiskusikan dalam satu waktu dan akhirnya membuat siswa tidak paham dengan materi yang sedang dipelajari. Kemudian proses pembelajaran Student Centered Learning dengan menggunakan discovery learning membutuhkan waktu yang tidak 
HORIZON

PENDIDIKAN

JURNAL HORIZON PENDIDIKAN

Publish by: Library of STKIP PGRI Sumatera Barat

E-ISSN : 2775-5770

Vol. 1 No. 4 (November 2021) (647-657)

http://ejournal.stkip-pgri-sumbar.ac.id/index.php/horizon

sebentar yang mana dalam proses

pembelajaran guru melakukan

pendahuluan dengan mengucapkan

salam, menanyakan kbar siswa,

mengambil absensi, menyebutkan

materi yang akan dipelajari.

Pada kegiatan inti proses pembelajaran yang dilakukan adalah diskusi tanya jawab yang menuntut siswa harus berfikir kritis dan aktif. Selama diskusi berlangsung guru memberikan pertanyan-pertanyaan mengenai materi pembeljaran dan siswa mencari jawabannya, sehingga siswa membutuhkan waktu untuk mencari jawabannya tersebut. Apalagi jika ada siswa yang tidak mengerti dengan pembelajaran maka guru harus menjelaskan kepada siswa agar tujuan pembelajaran tercapai. Terakhir pada kegiatan penutup guru dan siswa menyimpulkan pembelajaran yang sudah dibahas, kemudian guru memberikan masukan-masukan kepada siswa mengenai pembelajaran dan guru memberikan tugas kepada siswa, sehingga dalam kegiatan penutup ini juga membutuhkan waktu.
Teori yang digunakan dalam penelitian ini adalah teori konstruktivisme. Merupakan teori yang sudah tidak asaing lagi bagi dunia pendidikan, sebelum mengatahui lebih jauh tentang teori konstrukstivisme alangkah baiknya diketahui dulu konstruktivisme itu sendiri. Konstruktivisme berarti bersifat membangun. Dalam konteks filsafat pendidikan, konstruktivisme adalah suatu upaya membangun tata susuanan hidup yang berbudaya modren.

Berdasarkan penjelasan tersebut diatas, bahwa konstrukstivisme merupakan sebuah teori yang sifatnya membangun, membangun dari segi kemampuan, pemahaman, dalam proses pembelajaran. Sebab dengan memiliki sifat membangun maka dapat diharapkan keaktifan dari pada siswa akan meningkatkan kecerdasanya.

Menurut teori ini masyarakat merupakan suatu sistem sosial yang terdiri atas bagian-bagian atau elemen yang saling berkaitanan saling menyatu dalam keseimbangan. Perubahan yang terjadi pada suatu bagian akan 
Publish by: Library of STKIP PGRI Sumatera Barat

E-ISSN : 2775-5770

Vol. 1 No. 4 (November 2021) (647-657)

http://ejournal.stkip-pgri-sumbar.ac.id/index.php/horizon

membawa perubahan pula terhadap bagian yang lain. Teori yang menjadi dasar penggunaan model pembelajaran kooperatif adalah teori belajar konstruktivisme. Teori ini menjelaskan bahwa pengetahuan seseorang akan suatu benda, bukanlah tiruan benda itu, melainkan konstruksi pemikiran seseorang akan benda tersebut). Tidak adanya keaktifan seseorang dalam mencerna dan membentuknya seseorang tidak akan mempunyai pengetahuan oleh karenanya Piaget menyatakan secara ekstrem bahwa pengetahuan tidak dapat ditransfer dari otak pendidik/ pengajar yang dianggap tahu bila murid tidak mengolah dan membentuknya sendiri. Proses pembentukan pengetahuan ini terjadi apabila seseorang mengubah 15 atau mengembangkan skema yang telah dimiliki berhadapan dengan tantangan, rangsangan atau persoalan (Prasetyo ZK.)

Tobin dan Timmons dalam Prasetyo ZK. (2011) menekankan bila pembelajaran yang didasarkan pada pandangan konstruktivisme wajib memperhatikan 4 hal yaitu : terkait dengan pengetahuan awal (Prior knowledge), belajar berdasarkan dari pengalaman

(experience),

melibatkan interaksi antara sesama (Social interaction) dan rasa pemahaman (sense making). Adapun implikasi dari pembelajaran model konstruktivisme menurut Karli dan Nursobah A meliputi 4 tahapan yaitu :

a) Apersepsi, di step ini peserta didik didorong untuk mengemukakan pengetahuan awalnya tentang konsep yang dibahas, bila perlu pengajar memancing dan memberikan pertanyaan- pertanyaan tentang fenomena yang sering terjadi dalam kehidupan sehari-hari dengan mengaitkan konsep yang akan dibahas. Peserta didik diberikan peluang untuk mengungkapkan, menggambarkan pemahamannya mengenai konsep yang dipikirkannya.

b) Eksplorasi, di step ini peserta didik diberikan peluang untuk melakukan investigasi dan mendapatkan konsep melalui pengumpulan data serta informasi dalam suatu aktivitas yang telah 
Publish by: Library of STKIP PGRI Sumatera Barat

E-ISSN : 2775-5770

Vol. 1 No. 4 (November 2021) (647-657)

http://ejournal.stkip-pgri-sumbar.ac.id/index.php/horizon

16 dipersiapkan oleh pengajar kemudian secara tim mendiskusikannya dengan tim yang lain.

c) Diskusi dan penjelasan konsep, pada step ini saat peserta didik memberikan penjelasan dan pemecahan masalah atas dasar hasil observasi/investigasi selanjutnya dijustifikasi melalui penjelasan pengajar,sehingga peserta didik menjadi yakin dengan konsep pembelajaran yang dipahaminnya.

d) Pengembangan serta aplikasi, pada step ini pengajar berupaya membangun suasana pembelajaran yang kondusif, memungkinkan peserta didik dapat menerapkan pengetahuan atas konsep yang dipelajarinya melalui aktivitasaktivitas atau diskusi .

\section{KESIMPULAN}

Berdasarkan hasil penelitian yang telah peneliti lakukan dapat disimpulkan bahwasanya pelaksanaan Student Centered Learning berbasis online learning bisa dilaksanakan melalui teknologi informasi WhatsApp Group di SMA PGRI 4
Padang. Hal ini terlihat dari proses pembelajaran yang dijalankan menuntut keaktifan siswa selama proses dan menuntut siswa harus berfikir kritis dalam mencari jawabanya dari tugas yang diberikan oleh guru. Kemudian dalam pelaksanaannya terdapat kendalakendala yang dirasakan guru baik itu dari segi pengalokasian waktu maupun kemampuan guru sosiologi dalam menggunakan teknologi informasi yang terbatas.

\section{DAFTAR PUSTAKA}

Bungin B. Metodologi Penelitian Kualitatif. Raja Grafindo; 2012.

Kemendikbud RI. urat Edaran Nomor 4 Tahun 2020 Tentang Pelaksanaan Kebijakan Pendidikan Dalam Masa Darurat Penyebaran Coronavirus Disease (Covid19). Published online 2020:13.

Kemendikbud RI. Permendikbud Nomor 103 Tahun 2014 Tentang Pembelajaran Pada Pendidikan Dasar dan Pendidikan Menengah. Published online 2014.

Nursobah A. Implementasi Kurikulum 2013 dalam Meningkatkan Prestasi 
PENDIDIKAN

\section{JURNAL HORIZON PENDIDIKAN}

Publish by: Library of STKIP PGRI Sumatera Barat

E-ISSN : 2775-5770

Vol. 1 No. 4 (November 2021) (647-657)

http://ejournal.stkip-pgri-sumbar.ac.id/index.php/horizon

Belajar Siswa (Studi Multi

Situs di MIN Ngepoh

Tanggunggunung dan MIN

Mergayu Bandung

Tulungagung). J Dirasah.

Published online 2018:1(2),

40-51.

Prasetyo ZK. Pembelajaran dan Kompetensi Pendidik Abad-21.

In: Pembelajaran Dan

Kompetensi Pendidik Abad-21. ; 2017:2-8.

Rahardjo et al., 2011. Pembelajaran

Sosiologi. Jakarta. Rineka

Cipta. 